\title{
BMJ Open Ideal cardiovascular health in urban Jamaica: prevalence estimates and relationship to community property value, household assets and educational attainment: a cross-sectional study
}

Joette A McKenzie, ${ }^{1}$ Novie O Younger, ${ }^{1}$ Marshall Kerr Tulloch-Reid, ${ }^{1}$ Ishtar Govia, ${ }^{1}$ Nadia R Bennett, ${ }^{1}$ Shelly McFarlane, ${ }^{2}$ Renee Walters, ${ }^{1}$ Damian K Francis, ${ }^{3}$ Karen Webster-Kerr, ${ }^{4}$ Andriene Grant, ${ }^{4}$ Tamu Davidson, ${ }^{4}$ Rainford Wilks, ${ }^{1}$ David R Williams, ${ }^{5}$ Trevor S Ferguson (i) ${ }^{1}$

To cite: McKenzie JA, Younger NO, Tulloch-Reid MK, et al. Ideal cardiovascular health in urban Jamaica: prevalence estimates and relationship to community property value, household assets and educational attainment: a cross-sectional study. BMJ Open 2020;10:e040664. doi:10.1136/ bmjopen-2020-040664

- Prepublication history and additional material for this paper are available online. To view these files, please visit the journal online (http://dx.doi. org/10.1136/bmjopen-2020040664).

Received 20 May 2020 Revised 15 November 2020 Accepted 19 November 2020

D) Check for updates

(c) Author(s) (or their employer(s)) 2020. Re-use permitted under CC BY-NC. No commercial re-use. See rights and permissions. Published by BMJ.

For numbered affiliations see end of article.

\section{Correspondence to}

Dr Trevor S Ferguson; trevor.ferguson02@uwimona. edu.jm

\section{ABSTRACT}

Objective Ideal cardiovascular health $(\mathrm{ICH})$ is associated with greater longevity and reduced morbidity, but no research on ICH has been conducted in Jamaica. We aimed to estimate the prevalence of $\mathrm{ICH}$ in urban Jamaica and to evaluate associations between ICH and community, household, and individual socioeconomic status (SES).

Design Cross-sectional study.

Setting Urban communities in Jamaica.

Participants 360 men and 665 women who were urban residents aged $\geq 20$ years from a national survey, the Jamaica Health and Lifestyle Survey 2016-2017.

Exposures Community SES, using median land values (MLV); household SES, using number of household assets; and individual SES, using education level.

Primary outcome The main outcome variable was $\mathrm{ICH}$, defined as having five or more of seven ICH characteristics (ICH-5): current non-smoking, healthy diet, moderate physical activity, normal body mass index, normal blood pressure, normal glucose and normal cholesterol. Prevalence was estimated using weighted survey design and logistic regression models were used to evaluate associations.

Results The prevalence of overall ICH (seven characteristics) was $0.51 \%$, while the prevalence of $\mathrm{ICH}$ 5 was $22.9 \%$ (male $24.5 \%$, female $21.5 \%$, $p=0.447$ ). In sex-specific multivariable models adjusted for age, education, and household assets, men in the lower tertiles of community MLV had lower odds of ICH- 5 compared with men in the upper tertile (lowest tertile: OR $0.33,95 \% \mathrm{Cl} 0.12$ to $0.91, \mathrm{p}=0.032$; middle tertile: OR $0.46,95 \% \mathrm{Cl} 0.20$ to $1.04, p=0.062$ ). Women from communities in the lower and middle tertiles of MLV also had lower odds of ICH-5, but the association was not statistically significant. Educational attainment was inversely associated with ICH-5 among men and positively associated among women.

Conclusion Living in poorer communities was associated with lower odds of ICH-5 among men in Jamaica. The association between education level and ICH- 5 differed in men and women.
Strengths and limitations of this study

- This was a population-based study and was designed to be representative of the general urban population in Jamaica.

- Estimates were weighted to account for the complex survey design, thus ensuring that we can generalise the findings to urban Jamaica.

- A complete picture of property value includes that of the house and associated lands, rather than the unimproved land value, which was used in this study; however, we expect that land values will be highly correlated with house and total property value.

- The study had missing data for some variables; however, we used multiple imputation to fill in missing data, reducing potential bias and improving the power of the study.

\section{INTRODUCTION}

The American Heart Association (AHA), in 2010, recommended that in responding to the public health burden of cardiovascular disease (CVD), the focus should be more on preserving cardiovascular health rather than reducing disease. ${ }^{1}$ In light of this position, the AHA introduced the concept of ideal cardiovascular health (ICH), defined as having seven characteristics, comprising both health behaviours and health factors, namely current non-smoking, body mass index (BMI) $<25 \mathrm{~kg} / \mathrm{m}^{2}$, at least $150 \mathrm{~min}$ of moderate physical activity, healthy diet, normal blood pressure, normal glucose and normal cholesterol levels. ${ }^{1}$ The concept of ICH is believed to be a more far-reaching approach to the promotion of cardiovascular health and is based on data which suggest that persons with low levels of CVD risk factors in mid-life have significantly 
reduced risk of CVD and total mortality, and longer life expectancy. ${ }^{1-3}$ Since the publication of the AHA definition of ICH, several studies have sought to estimate the prevalence of ICH in various populations. Overall the prevalence of ICH (ie, having all seven components) is low in most populations, with prevalence estimates often $<1 \%{ }^{4-10}$ Given the low prevalence of all seven ICH components, several investigators have used operational definitions for ICH as having five to seven components, or performed analyses with the number of ICH components as the outcome variable. ${ }^{5-8} 10$

CVD risk factor prevalence is high in poor urban communities, and urbanisation has been identified as one of the factors driving the non-communicable disease epidemic. ${ }^{11-16}$ However, research on cardiovascular health in low-income and middle-income countries (LMICs) remains limited.

An increasing number of studies now explore neighbourhood characteristics to assess socioeconomic status (SES) in communities. ${ }^{17}$ Property value is also emerging as a useful means of assessing SES, ${ }^{18} 19$ sometimes using data from tax-related agencies and national censuses. ${ }^{20}$ In Britain, the council tax valuation band is used to assess SES, ${ }^{19}$ along with unimproved land value, household value, overcrowding and household tenure. ${ }^{21-24}$ Although non-traditional, several of these measures have been shown to be comparable with income and other SES indices. ${ }^{25}$ Property value can be considered as an indicator of wealth; studies have shown the strong association between property value and other markers of SES previously used as measures of wealth. ${ }^{27} 28$

Jamaica is classified as an upper middle-income country but has a large number of poor 'inner city' communities with poverty estimated at $17 \% .^{29}{ }^{30}$ Previous studies have documented high prevalence of CVD risk factors in Jamaica with significant socioeconomic disparities. ${ }^{31}{ }^{32}$ To date, there have been no published data on the prevalence of ICH or its components or on the relationship between ICH and community or household SES.

In this paper we report prevalence estimates of ICH and its individual components in urban Jamaica and evaluate the relationship between ICH and community, household, and individual SES. Specifically, we evaluated the association between having five or more ICH characteristics (ICH-5) and community median property value, number of household assets, and individual educational attainment.

\section{METHODS}

\section{Study design and data sources}

We conducted a cross-sectional study using data from the Jamaica Health and Lifestyle Survey 2016-2017 (JHLS III), a national health examination survey, with Jamaicans 15 years and older as eligible participants. Trained data collectors used an interviewer-administered questionnaire to obtain data on demographic characteristics, medical history, and health behaviours including dietary practices and physical activity. Blood pressure and anthropometric measurements were done at the participant's home and followed standardised procedures. A capillary blood sample was collected in the fasting state to measure glucose and cholesterol. For this study, we included urban participants 20 years and older, given that the study was focused on cardiovascular health among adults in urban communities and we used the adult definitions of ICH. Data related to the seven ICH characteristics were extracted from the main JHLS III datafile along with demographic data including age, sex, educational attainment and household assets. Participants provided written informed consent prior to data collection.

Data on property value were obtained from the National Land Agency (NLA) (http://www.nla.gov.jm/content/ background), the governmental body responsible for property valuation in Jamaica. Data were extracted by overlaying a shapefile of all the enumeration districts (EDs) surveyed in the JHLS III to a central database of properties in Jamaica. The shapefile was procured from the Statistical Institute of Jamaica (STATIN), the governmental body responsible for defining ED boundaries. STATIN also provided data on the communities to which each ED belonged based on the community classification by the Social Development Commission, a government agency responsible for community organisation and development.

The unimproved land value data for each property within the boundaries of the EDs were added to the shapefile by the NLA and data exported to a spreadsheet. Property values were quoted in Jamaican dollars and parcels classified as either residential or commercial. Data for 25645 parcels of land from 169 EDs spanning 151 communities were obtained and used to compute the median property value for each community.

\section{Patient and public involvement}

There was no direct patient or public involvement in the design or conduct of the study. Results will be disseminated to the communities through meetings with community members or citizens associations.

\section{Measurement of ICH variables}

Blood pressure was measured using an oscillometric device (Omron 5 Series Blood Pressure Monitor, Omron Healthcare, Lake Forest, Illinois). Three measurements were taken in the right arm after the participant had been seated for $5 \mathrm{~min}$ and followed standardised procedures developed for the International Collaborative Study of Hypertension in Blacks. ${ }^{33}$ Field staff were trained and certified prior to starting fieldwork and at 3-month intervals to ensure reliable measurements. The means of the second and third systolic blood pressure (SBP) and diastolic blood pressure (DBP) measurements were used in the analyses. Weight was measured using a portable digital scale (Tanita HD-351 Digital Weight Scale, Tanita Corporation, Tokyo, Japan) and recorded to the nearest $0.1 \mathrm{~kg}$. Height was measured using a portable stadiometer 
(Seca 213 Mobile stadiometer, Seca, Hamburg, Germany) and recorded to the nearest $0.1 \mathrm{~cm}$. Fasting glucose and total cholesterol were measured from a capillary blood sample using a point of care device (SD LipidoCare, Suwon, South Korea); details on this device are available at the company website (http://sdbiosensor.com/xe/ product/2601). Data on smoking status, physical activity, and dietary practices were obtained via intervieweradministered questionnaire.

\section{Variable creation and definitions}

Dichotomous variables for each of the seven ICH components were created using definitions from the AHA. ${ }^{1}$ Normal blood pressure was defined as SBP $<120 \mathrm{~mm} \mathrm{Hg}$ and $\mathrm{DBP}<80 \mathrm{~mm} \mathrm{Hg}$ for persons not on medication for hypertension. BMI was computed as weight in kilograms divided by the square of height in metres and normal BMI was defined as BMI $<25.0 \mathrm{~kg} / \mathrm{m}^{2}$. Normal glucose was defined as fasting glucose $<5.6 \mathrm{mmol} / \mathrm{L}$ among persons not on medication for diabetes and normal cholesterol as cholesterol $<5.2 \mathrm{mmol} / \mathrm{L}$ among persons not on medication for hypercholesterolaemia. Persons who reported never smoking or having quit for greater than 12 months were classified as current non-smokers. Adequate physical activity was defined as engaging in at least $150 \mathrm{~min}$ of moderate physical activity or $75 \mathrm{~min}$ of vigorous activity each week. The healthy diet definition was modified based on the data that were collected for JHLS III as we did not have data on whole grain intake. Participants were therefore classified as having a healthy diet if they had three or more of the following dietary characteristics: (1) low-salt diet, defined as no added salt at the table and rarely or never eats processed foods; (2) low sugarsweetened beverage (SSB) consumption, defined as SSB intake less than twice per week; (3) adequate fruit and vegetable consumption, defined as intake of fruits or vegetables three or more times per day; and (4) adequate fish consumption, defined as eating fish two or more times per week.

From the seven ICH characteristics we created dichotomous variables for having all seven ICH characteristics (ICH-7), five or more ICH characteristics (ICH-5), four ICH health behaviours (adequate physical activity, nonsmoker, normal BMI and healthy diet) and four ICH health factors (normal blood pressure, normal glucose, normal cholesterol and current non-smoker).

Educational attainment was used as a measure of individual level SES, based on participants' responses to a question on the highest level of education reached. Responses were categorised as 'less than high school' for persons reporting no education, elementary/primary school education or junior secondary school education (up to grade 8); 'high school' for participants reporting at least some secondary level education (grades 9-13); and 'more than high school' for those reporting at least some postsecondary school education, whether through college, university or vocational training institutions.
Household SES was assessed based on participants' responses to whether they had a list of 22 household assets. The full list of items is shown in online supplemental table S1. We created tertiles of the number of household assets for use in the analyses. Tertile 1 included persons with 9 or fewer household assets, tertile 2 included those with 10-12 items, and tertile 3 included persons with 13-22 items.

Property values for each community were ranked and the median value was selected as a summative measure for the community. Community median property values were then ranked (stratified by rural/urban category) and categorised into land value tertiles-lower, middle and upper-and used for further analysis.

\section{Sample size}

Our original sample size calculations are available in the study protocol. ${ }^{34}$ The total available sample for this study was 1025 persons. We estimated a design effect of 2.6 based on the ratio of the variance for the proportion of participants with five ICH components with and without adjustment for survey design in JHLS 2007-2008. This resulted in an effective sample size of 394 . We estimated that this effective sample size had $85 \%$ power to detect a prevalence gradient of $6 \%, 12 \%$ and $18 \%$ going from high to low SES groups, with $\alpha$ of 0.05 .

\section{Statistical analysis}

Data analyses were performed using Stata V.14.2 software. Survey weights were used to account for survey design and the age and sex distribution of the Jamaican population. Descriptive statistics were computed for outcome and exposure variables and for potential confounders. Differences in characteristics across sex categories, land value tertiles, education categories, and household possession categories were compared using t-tests, one-way analysis of variance, or $\chi^{2}$ test as appropriate. The prevalence of each ICH component, having all seven ICH components, and five or more ICH components was estimated within and across sex and SES categories. There was evidence of sex interaction in the association between ICH- 5 and education; we therefore presented sex-specific estimates in the models for education and in the multivariable models. Multiple logistic regression was used to quantify the sex-specific association between those with five or more ICH characteristics (ICH-5) and exposure variables (land value tertiles, education category and household possession categories) with adjustment for age.

The JHLS III data set included 1167 urban participants. Analyses for this paper were limited to participants $\geq 20$ years old with available data on age, sex, survey weights and at least one ICH characteristic. This resulted in a data set of 1025 participants for analysis. Statistical significance was set at two-sided $\mathrm{p}<0.05$.

Multiple imputation was used to account for missing data. Of the 1025 participants, 435 (42\%) had no missing values for 22 variables selected for use in the analyses, while 590 participants $(58 \%)$ had one or more missing 
values. Except for slightly higher proportion of persons with low-salt diet, low SSB consumption and more than high school education, there were no other significant differences between participants with missing data and those with non-missing data. The number and proportion of missing values for the main variables included in the analyses are shown in online supplemental table S2. Proportion of missing values was mostly less than $10 \%$, except for BMI (11\%), fasting glucose (26\%), fasting cholesterol (28\%) and smoking history (32\%). While complete case analysis (list-wise deletion of missing data) may have been a valid approach to dealing with missing data, this approach results in loss of power and potential selection bias; we therefore chose to use multiple imputation to deal with missing data in this paper. ${ }^{356} \mathrm{We}$ generated 32 imputed data sets, such that the number of imputations would be at least equal to the highest proportion of incomplete cases, representing an adaptation of a rule of thumb suggested by White and colleagues. ${ }^{36}$
Imputation models included all the variables for inclusion in multivariable models. Bivariate and multivariable models were created using Stata's mi estimate command using the 32 multiply imputed data sets; estimates were combined by the software using Rubin's rules. ${ }^{37} 38$

We also performed sensitivity analyses to assess whether the associations found would remain if assessed differently. The specific additional models included (1) twolevel multilevel models with community as the cluster variable; (2) analysis of covariance (ANCOVA) model using the number of ICH components as the outcome variable; and (3) complete case analysis (ie, model with no imputed values).

\section{RESULTS}

The analysed sample included 1025 participants (360 men, 665 women) with a mean age $( \pm \mathrm{SD})$ of $47 \pm 17.5$ years. Summary statistics for participant characteristics are

\begin{tabular}{|c|c|c|c|c|}
\hline Characteristics & & $\begin{array}{l}\text { Male } \\
(n=360)\end{array}$ & $\begin{array}{l}\text { Female } \\
(n=665)\end{array}$ & $\begin{array}{l}\text { Total } \\
(\mathrm{N}=1025)\end{array}$ \\
\hline Mean for continuous variables & $\mathrm{n} \dagger$ & Mean (SD) & Mean (SD) & Mean (SD) \\
\hline Age (years) & 1025 & $47.1(18.1)$ & $47.1(17.2)$ & $47.1(17.5)$ \\
\hline Height $(\mathrm{cm})^{\star * *}$ & 937 & $172.3(7.4)$ & $161.3(8.3)$ & $165.1(9.5)$ \\
\hline Weight (kg) & 934 & $76.9(24.0)$ & $80.0(25.5)$ & $78.9(25.0)$ \\
\hline $\operatorname{BMI}\left(\mathrm{kg} / \mathrm{m}^{2}\right)^{\star \star \star *}$ & 917 & $25.9(7.9)$ & $30.8(10.0)$ & $29.1(9.7)$ \\
\hline Systolic blood pressure $(\mathrm{mm} \mathrm{Hg})^{\star \star}$ & 956 & $133.5(21.1)$ & $129.1(22.6)$ & $130.6(22.2)$ \\
\hline Diastolic blood pressure & 956 & $84.6(13.4)$ & $83.6(12.6)$ & $83.9(12.9)$ \\
\hline Fasting glucose & 764 & $5.7(1.4)$ & $5.9(2.1)$ & $5.8(1.9)$ \\
\hline \multirow[t]{2}{*}{ Total cholesterol } & 729 & $4.5(1.1)$ & $4.5(1.1)$ & $4.5(1.1)$ \\
\hline & & Median (IQR) & Median (IQR) & Median (IQR) \\
\hline Median land value (million JMD) & 969 & $1.5(0.9-2)$ & $1.35(0.9-2)$ & $1.4(0.9-2)$ \\
\hline Proportions for categorical variables & & $\%(n)$ & $\%(n)$ & $\%(n)$ \\
\hline Cigarette smoking ${ }^{\star \star \star}$ & 681 & $21.2(51)$ & $6.1(27)$ & $11.4(78)$ \\
\hline Education $^{* \star *}$ & 992 & & & \\
\hline Less than high school & & $30.4(107)$ & $20.9(134)$ & $24.3(241)$ \\
\hline High school & & $50.9(179)$ & $51.7(331)$ & $51.4(510)$ \\
\hline More than high school & & $18.8(66)$ & $27.3(175)$ & $24.3(241)$ \\
\hline Number of household assets (tertiles) & 1021 & & & \\
\hline Lower tertile ( $\leq 9$ items) & & $42.2(151)$ & $40.7(270)$ & $41.3(421)$ \\
\hline Middle tertile (10-12 items) & & $34.1(122)$ & $29.3(194)$ & $31.0(316)$ \\
\hline Upper tertile (13-22 items) & & $23.7(85)$ & 30.0 (199) & $27.8(284)$ \\
\hline Median land value tertiles & 969 & & & \\
\hline Lower tertile (<1 million JMD) & & 35.4 (122) & $39.4(246)$ & $38.0(368)$ \\
\hline Middle tertile (1-2 million JMD) & & $40.0(138)$ & $36.9(230)$ & $38.0(368)$ \\
\hline Upper tertile (>2-9 million JMD) & & $24.6(85)$ & $23.7(148)$ & $24.1(233)$ \\
\hline
\end{tabular}

${ }^{* *} \mathrm{P}<0.01,{ }^{* * *} \mathrm{P}<0.001$ for male and female differences.

$\mathrm{tn}$ is the number of available values for each variable.

BMI, body mass index; JMD, Jamaican dollars. 
Table 2 Mean number of $\mathrm{ICH}$ characteristics, prevalence of overall ICH and individual ICH components among urban participants of the Jamaica Health and Lifestyle Survey III, by sex

\begin{tabular}{|c|c|c|c|}
\hline Characteristics & $\begin{array}{l}\text { Total } \\
\text { (N=1025) }\end{array}$ & $\begin{array}{l}\text { Male } \\
(n=360)\end{array}$ & $\begin{array}{l}\text { Female } \\
(n=665)\end{array}$ \\
\hline Mean number of $\mathrm{ICH}$ characteristics & 3.6 (3.5 to 3.7$)$ & 3.6 (3.4 to 3.8$)$ & 3.6 (3.5 to 3.7$)$ \\
\hline All $7 \mathrm{ICH}$ characteristics $\dagger$ & $0.51(0$ to 1.1$)$ & - & - \\
\hline 5 or more $\mathrm{ICH}$ characteristics & 22.9 (18.9 to 26.9$)$ & 24.5 (17.5 to 31.6$)$ & $21.5(17.5$ to 25.6$)$ \\
\hline All $4 \mathrm{ICH}$ : health behaviours & $4.1(2.2$ to 6.0$)$ & $6.4(2.6$ to 10.3$)$ & 2.0 (0.8 to 3.3$)$ \\
\hline All $4 \mathrm{ICH}$ : health factors & $14.2(11.0$ to 17.4$)$ & $10.6(5.0$ to 16.3$)$ & $17.3(13.5$ to 21.0$)$ \\
\hline Normal blood pressure $(<120 / 80 \mathrm{~mm} \mathrm{Hg})^{\star \star \star}$ & 28.7 (24.9 to 32.4$)$ & 20.8 (14.6 to 26.9$)$ & 35.6 (31.5 to 39.6$)$ \\
\hline Normal BMI $\left(<25 \mathrm{~kg} / \mathrm{m}^{2}\right)^{\star \star \star}$ & 31.1 (26.3 to 35.9$)$ & 39.7 (31.2 to 48.2$)$ & 23.5 (19.3 to 27.6$)$ \\
\hline Normal glucose $(<5.6 \mathrm{mmol} / \mathrm{L})$ & 53.7 (48.3 to 59.0$)$ & 53.2 (43.6 to 62.8$)$ & $54.1(48.2$ to 59.9$)$ \\
\hline Normal cholesterol $(<5.2 \mathrm{mmol} / \mathrm{L})$ & $77.4(72.9$ to 81.8$)$ & 78.7 (71.8 to 85.6$)$ & $76.2(71.0$ to 81.5$)$ \\
\hline Physical activity $\geq 150 \mathrm{~min} /$ week $^{\star \star \star}$ & 59.1 (54.2 to 63.9$)$ & 67.5 (61.1 to 73.9$)$ & $51.6(46.6$ to 56.6$)$ \\
\hline Healthy diet ( $\geq 3$ of 4 dietary factors) $\ddagger$ & 20.3 (17.3 to 23.3$)$ & 18.8 (14.0 to 23.6$)$ & $21.6(18.3$ to 25.0$)$ \\
\hline Current non-smoker* & 86.6 (82.8 to 90.3 ) & 79.8 (72.4 to 87.1$)$ & 92.6 (89.5 to 95.7 ) \\
\hline
\end{tabular}

Values reported are given as percentage with $95 \% \mathrm{Cl}$ in brackets, except for the mean number of ICH characteristics which is given as number with $95 \% \mathrm{Cl}$ in brackets.

$\mathrm{ICH}$ : health behaviours include adequate physical activity, non-smoker, normal BMI and healthy diet; ICH: health factors include normal blood pressure, normal glucose, normal cholesterol and current non-smoker.

${ }^{* *} \mathrm{P}<0.01,{ }^{* *} \mathrm{P}<0.001$ for male and female differences.

†There were too few persons with all $7 \mathrm{ICH}$ characteristics to compute sex-specific estimates.

fHealthy diet defined as meeting 3 or 4 of the following criteria: (1) adequate fruit and vegetable intake, (2) adequate fish intake, (3) low-salt diet and (4) low sugar-sweetened beverage consumption.

$\mathrm{BMI}$, body mass index; ICH, ideal cardiovascular health.

shown in table 1 . Men were significantly taller and had a lower BMI than their female counterparts $(\mathrm{p}<0.001)$. SBP was also significantly higher among men compared with women ( $133.5 \mathrm{~mm} \mathrm{Hg}$ vs $129.1 \mathrm{~mm} \mathrm{Hg}, \mathrm{p}<0.01)$. Men were three times more likely to be current cigarette smokers when compared with women $(21.2 \%$ vs $6.1 \%, \mathrm{p}<0.001)$. A greater proportion of men had less than high school education, while a higher proportion of women had high school or more than high school educational attainment. There were no significant sex differences in the distribution of household assets or community property value categories.

Summary statistics for characteristics stratified by tertiles of community median land value (MLV) are shown in online supplemental table S3. Except for height, there were no statistically significant differences in mean values for the assessed characteristics by MLV tertile. There was a statistically significant association between MLV tertiles and both educational attainment $(\mathrm{p}<0.001)$ and household assets $(\mathrm{p}<0.001)$. As expected, persons in the higher MLV tertiles were more likely to have higher educational attainment. Similarly, there were higher proportions of persons in the upper tertile of household assets in the higher categories of MLV.

The mean number of ICH characteristics and the prevalence estimates for overall ICH and other ICH metrics as well as the individual ICH components for all participants and within sex categories are shown in table 2 . The mean number of ICH characteristics was 3.6, with no significant sex differences. The overall prevalence of ICH (all seven characteristics, ICH-7) was $0.51 \%$, while the proportion of persons with $\geq 5$ ICH characteristics (ICH-5) was $22.9 \%$. Men had higher prevalence of ICH-5 (24.5\%) compared with women $(21.5 \%)$, but the difference was not statistically significant. We did not compute sex-specific estimates for ICH-7 as there were no men with ICH-7 in the non-imputed data. The proportions of participants having one to seven characteristics are shown in figure 1 . The

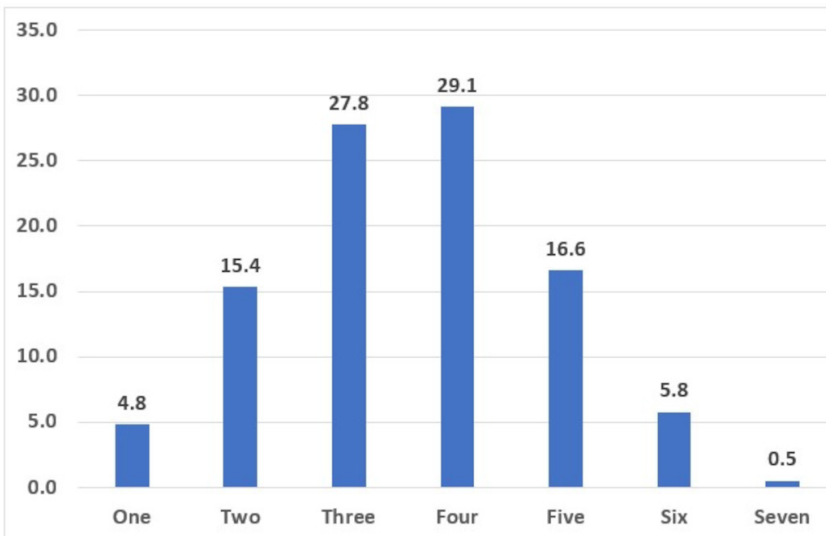

Figure 1 Proportion (\%) of participants with 1-7 ICH components. ICH components include current non-smoking, healthy diet, moderate physical activity, normal body mass index, normal blood pressure, normal glucose and normal cholesterol. ICH, ideal cardiovascular health. 
highest proportion was for four characteristics $(29.1 \%)$, followed by three characteristics $(27.8 \%)$. The prevalence of all four health behaviours was $4.1 \%$ and was higher in men compared with women $(6.4 \%$ vs $2.0 \%, \mathrm{p}=0.014)$. The prevalence for all four ideal health factors was $14.2 \%$ and was higher in women $(17.3 \%$ vs $10.6 \%)$, but the difference was not statistically significant. The prevalence of individual ICH characteristics ranged from a low of $20 \%$ for healthy diet to a high of $87 \%$ for non-smoking.

Summary statistics for the ICH characteristics described above, stratified by levels of community property value, household assets and individual educational attainment, are shown in online supplemental tables S4A-S4C. There were no significant associations between the mean number of ICH characteristics across MLV tertiles (online supplemental tables S4A). The prevalence of ICH-5 was higher in the upper and middle tertiles of MLV, but the differences were not statistically significant. The prevalence of all four ideal health behaviours was also higher in the middle and upper tertiles of MLV, this time achieving statistical significance for the lower MLV tertile when compared with the upper MLV tertile.

There were no significant differences between the mean number of ICH characteristics and tertiles of household assets (online supplemental table $\mathrm{S} 4 \mathrm{~B}$ ). The prevalence of ICH-5 was highest in the middle tertile of household assets and lowest in the lower tertile, but the differences were not statistically significant.

For educational attainment we report sex-specific estimates because there was evidence of sex interaction in the relationship between ICH-5 and education categories (online supplemental table $\mathrm{S} 4 \mathrm{C}$ ). Among men, the mean number of ICH characteristics and the proportion of ICH-5 were highest in the middle education (high school) category, with the difference in proportion for ICH-5 approaching statistical significance $(p=0.061)$. The prevalence of ideal health behaviours and ideal health factors was also highest among those with high school education, but again not statistically significant. Among women, there were statistically significant differences in the mean number of ICH characteristics and prevalence of ICH-5, with values highest among women with more than high school education and lowest among those with less than high school education.

Bivariate models yielding ORs for ICH-5 comparing levels of explanatory variables and potential confounders are shown in table 3 . We report sex-specific models, given the sex interaction between ICH-5 and education categories. Age was inversely associated with ICH-5 for both men and women. Persons in the lower MLV tertiles were less likely to have ICH-5, but this was not statistically significant in the bivariate models. Women with lower education were less likely to have ICH-5 $(p<0.05)$, while men with less education had non-significant higher odds of ICH-5 in bivariate models. No significant associations were seen for tertiles of household assets.

Table 4 shows the results for our final sex-specific multivariable model with ICH-5 as the outcome variable. Models include the three SES variables and age. We did not include the other cardiovascular risk variables as potential confounders since they were included in the determination of ICH. Men in the lowest tertile of community MLV had $67 \%$ lower odds of ICH-5 compared with those in the upper tertile $(\mathrm{p}=0.032)$, while men in the middle tertile had $54 \%$ lower odds of ICH-5 ( $\mathrm{p}=0.062)$. Women from communities in the lower and middle tertiles of MLV were also less likely to have ICH-5, $28 \%$ and $30 \%$ reduction in the odds of ICH, respectively, but this did not

Table 3 Odds ratios for $\geq 5$ ideal cardiovascular health characteristics among urban participants of the Jamaica Health and Lifestyle Survey (sex-specific bivariate models)

\begin{tabular}{|c|c|c|c|c|}
\hline \multirow{2}{*}{ Characteristics } & \multicolumn{2}{|l|}{ Male } & \multicolumn{2}{|l|}{ Female } \\
\hline & Odds ratios $(95 \% \mathrm{Cl})$ & $P$ value & Odds ratios (95\% Cl) & $P$ value \\
\hline Age (years) & 0.97 (0.95 to 0.99$)$ & 0.006 & $0.98(0.96$ to 1.00$)$ & 0.028 \\
\hline \multicolumn{5}{|l|}{ Median land value } \\
\hline Upper tertile (>2-9 million JMD) & 1.0 & & 1.0 & \\
\hline Middle tertile (1-2 million JMD) & $0.63(0.30$ to 1.31$)$ & 0.209 & 0.72 (0.39 to 1.33$)$ & 0.291 \\
\hline \multicolumn{5}{|l|}{ Household assets } \\
\hline Upper tertile (13-22 items) & 1.0 & & 1.0 & \\
\hline Middle tertile (10-12 items) & $1.51(0.64$ to 3.54$)$ & 0.335 & $1.14(0.65$ to 2.00$)$ & 0.637 \\
\hline Lower tertile ( $\leq 9$ items) & 0.76 (0.33 to 1.73$)$ & 0.505 & 0.85 (0.49 to 1.48$)$ & 0.556 \\
\hline \multicolumn{5}{|l|}{ Education category } \\
\hline Less than high school & $1.10(0.39$ to 3.15$)$ & 0.855 & $0.35(0.15$ to 0.84$)$ & 0.019 \\
\hline
\end{tabular}

JMD, Jamaican dollars. 
Table 4 Odds ratios for $\geq 5$ ideal cardiovascular health characteristics among urban participants of the Jamaica Health and Lifestyle Survey (multivariate models)

\begin{tabular}{|c|c|c|c|c|}
\hline \multirow{2}{*}{ Characteristics } & \multicolumn{2}{|l|}{ Male } & \multicolumn{2}{|l|}{ Female } \\
\hline & Odds ratios $(95 \% \mathrm{Cl})$ & P value & Odds ratios $(95 \% \mathrm{Cl})$ & $P$ value \\
\hline \multicolumn{5}{|l|}{ Median land value } \\
\hline Middle tertile (1-2 million JMD) & $0.46(0.20$ to 1.04$)$ & 0.062 & $0.70(0.37$ to 1.32$)$ & 0.271 \\
\hline Lower tertile (<1 million JMD) & $0.33(0.12$ to 0.91$)$ & 0.032 & 0.72 (0.38 to 1.34$)$ & 0.295 \\
\hline Upper tertile (13-22 items) & 1.0 & & 1.0 & \\
\hline Middle tertile (10-12 items) & 1.58 (0.68 to 4.09$)$ & 0.340 & 1.41 (0.69 to 2.88$)$ & 0.346 \\
\hline Lower tertile ( $\leq 9$ items) & 0.81 (0.31 to 2.09$)$ & 0.658 & 1.16 (0.63 to 2.13$)$ & 0.635 \\
\hline \multicolumn{5}{|l|}{ Education category } \\
\hline More than high school & 1.0 & & 1.0 & \\
\hline Age (years) & 0.96 (0.93 to 0.99$)$ & 0.004 & $0.98(0.95$ to 1.00$)$ & 0.092 \\
\hline
\end{tabular}

Separate models created for male and female participants in logistic regression models weighted for survey design using multiple imputation to account for missing data. The model for male participants included 360 participants while the model for female participants included 665 participants.

JMD, Jamaican dollars.

achieve statistical significance. Educational attainment was inversely associated with ICH-5 among men (OR 3.16, $\mathrm{p}=0.079$ and OR 3.03, $\mathrm{p}=0.028$, for less than high school and high school, respectively, when compared with more than high school education). In contrast, there was a positive association between education level and ICH among women, with lower odds of ICH among those with less education (OR $0.40, \mathrm{p}=0.070$ for less than high school, and OR 0.51, $\mathrm{p}=0.016$, for high school, compared with more than high school education). There were no significant associations between the number of household assets and ICH-5 for either men or women.

For the sensitivity analysis, we reran our final model using the following variations: (1) using two-level multilevel models with community as the cluster variable; (2) using the number of ICH components as the outcome variable (ANCOVA model); and (3) using only complete cases (ie, model with no imputed values). These models are shown in online supplemental table S5-S7. The findings produced were generally similar to those from the final model shown in table 4 . In the complete case analysis, shown in online supplemental table S7, estimated ORs were less precise than those in the model with multiple imputation, with wider CIs and sometimes not achieving statistical significance.

\section{DISCUSSION}

In this study we have found that the prevalence of ICH is low in urban Jamaica, with only $0.5 \%$ of the population $\geq 20$ years having all seven ICH characteristics and 23\% having $\geq 5$ characteristics. Prevalent ICH-5 was associated with community SES measured by median property value. Poorer community SES (lower MLV) was associated with lower odds of ICH-5 among both men and women, but the association was statistically significant among men only. Men with less education had higher odds of ICH-5, while women with less education were less likely to have ICH-5.

The low prevalence of ICH as reported in this study has been seen in several other studies, with the prevalence of all seven ICH components being $<1 \%$ in most studies and the prevalence of five or more characteristics ranging between $4 \%$ and $37 \% .{ }^{6-9} 39-50$ A summary of estimates from published studies is shown in online supplemental table S8. The highest prevalence of five or more ICH characteristics was 37\% among French-speaking adults in Quebec, ${ }^{40}$ while the lowest prevalence was among black participants in the Jackson Heart Study. ${ }^{39}$ The prevalence varied with age and sex and was generally lower among men and among older persons. There were also some racial differences in the prevalence of ICH, with blacks having lower prevalence when compared with whites. ${ }^{43} 5051$

Several studies have reported socioeconomic differences in the prevalence of ICH. The majority of studies showed a direct relationship where higher SES was associated with higher prevalence of ICH or mean number of ICH characteristics. ${ }^{4041444545152}$ An analysis of data from the Multi-Ethnic Study of Atherosclerosis found that higher income and education were associated with higher prevalence of ICH and that higher neighbourhood physical, social and economic status were also associated with higher prevalence of $\mathrm{ICH}^{51}$ In contrast to the findings 
in other studies, a study from Peru found that persons in the middle and highest tertiles of a wealth index (derived from an aggregation of assets and household facilities) were less likely to have $\geq 5 \mathrm{ICH}$ components. ${ }^{44}$ We did not find any studies published that specifically assessed the association between property value and ICH.

In this study we used the MLV of the communities as a measure of community SES and found that community SES was directly associated with prevalence of $\geq 5 \mathrm{ICH}$ components. Although we did not find similar studies in the literature, our findings were in keeping with those of other studies which found people who live in lower SES urban neighbourhoods were more likely to have a greater burden of CVD.$^{53}$ The findings also corroborate the association between council tax valuation bands (a measure of property value in the UK) and CVD factors such as smoking, poor diet and obesity. ${ }^{19}$ Additionally, our study is consistent with another study which showed that relative location factor (derived from residential property value) was associated with five cardiometabolic risk factors (central obesity, hypertriglyceridaemia, reduced high-density lipoprotein cholesterol, diabetes/diabetic risk, hypertension) and overall cardiometabolic risk score in Australia. ${ }^{27}$ Our study demonstrates that using property value data from government agencies such as the NLA can circumvent the challenges encountered when collecting epidemiological data used to estimate SES.

While level of educational attainment and ICH-5 had a positive relationship for women, the reverse was true for men. Looking at the sex-specific proportions for MLV, it was noted that more men were found to live in the middle and upper MLV communities than women. It was also found that women were more likely to have higher education than their male counterparts. It is possible that the lower prevalence of ICH- 5 among men with higher education may be driven by a higher prevalence of obesity and metabolic syndrome in men of higher SES, which has been previously reported by our team. ${ }^{55}$ As shown in online supplemental table S4C, men with higher education had lower prevalence of normal BMI, physical activity and healthy diet. These may reflect more sedentary work activities and less time for physical activity and preparing healthy meals. The opposite may often be true for higher SES women, who are more likely to be health-conscious and thus pay greater attention to diet and participate in leisure time physical activity such as going to the gym.

In this study we did not find an association between household assets and ICH. In a previous study we found a significant inverse association between elevated blood pressure and hypertension for women only. ${ }^{57}$ Similar to our findings, the Prospective Urban Rural Epidemiology study found that education was more strongly associated with CVD than was household wealth based on an index which included ownership of assets and housing characteristics. $^{58}$

There were some limitations to this study. First, a complete picture of property value includes that of the house and associated lands, rather than the unimproved land value which was used in this study. It is however expected that land values will be highly correlated with house and total property value and when used for classification into categories as used in this study will correctly classify community SES. Additionally, we did not consider housing tenure, or property ownership, but we believe that the contextual effects of community SES will still be relevant whether or not one owns the property in which he or she resides. The study was also limited by missing data for some variables. We were, however, able to use multiple imputation to fill in missing data and perform analyses using the multiple imputed data. This approach reduces potential bias when compared with a complete case analysis and improves the power of the study to show significant associations. ${ }^{3659}$ We also performed sensitivity analyses using only complete cases and found that the direction of association and effect sizes were generally similar, thus indicating that the use of multiple imputation, while improving the power of the study, did not alter the inferences made in the study. Finally, the crosssectional design limits our ability to make causal inference; however, the findings make a useful contribution to our understanding of the associations between SES and cardiovascular health.

The strengths of the study include the fact that it was a population-based study and that it was designed to be representative of the general urban population in Jamaica. Estimates were weighted to account for the complex survey design, thus ensuring that we can generalise the findings to urban Jamaica. Additionally, the study used standardised methods for measurements and data collection to ensure high data quality.

With regard to public health implications, the low prevalence of ICH reported in this study suggests that there is a need to promote ICH in urban Jamaica. This could be achieved through government agencies, nongovernmental organisations and health advocacy groups implementing public health activities and policies to facilitate improvements in cardiovascular health among Jamaicans. Such programmes should target low-income urban communities, but there is need for intervention in middle-income and upper-income communities as well, given the low prevalence of ICH in all community income groups. Focus could be on achieving a healthy diet, normal blood pressure and normal BMI, as these were the least common ICH characteristics. Strategies should also take into consideration sex differences in ICH components and associations. While these implications are directly relevant to Jamaica, it is likely that these measures may also be applicable to other LMICs with sociodemographic characteristics similar to Jamaica.

\section{CONCLUSION}

Among urban Jamaicans, the prevalence of all seven ICH characteristics was less than $1 \%$, while only $23 \%$ of the population had five or more characteristics. Persons who live in poorer communities were less likely to attain 
ICH-5. Higher education was associated with higher odds of ICH-5 among women but lower odds among men. We recommend that SES be considered when planning initiatives to promote cardiovascular health, especially among urban-dwelling populations. Our data suggest that these efforts may be most effective among Jamaican men and women from poorer communities and among men with higher education.

\section{Author affiliations}

${ }^{1}$ Epidemiology Research Unit, Caribbean Institute for Health Research, University of the West Indies, Kingston, Jamaica

${ }^{2}$ Tropical Metabolism Research Unit, Caribbean Institute for Health Research, University of the West Indies at Mona, Kingston, Saint Andrew, Jamaica ${ }^{3}$ School of Health and Human Performance, Georgia College and State University, Milledgeville, Georgia, USA

${ }^{4}$ Office of the Prinicpal Medical Officer, National Epidemiology Unit and NonCommunicable Diseases and Injuries Prevention Unit, Ministry of Health and Wellness, Kingston, Jamaica

${ }^{5}$ Department of Social and Behavioral Sciences, Harvard University T H Chan School of Public Health, Boston, Massachusetts, USA

Acknowledgements The authors would like to thank the Harvard T H Chan School of Public Health Lown Scholars Program for the grant and general support. The authors also thank the National Land Agency (NLA) for providing the property value data and the Statistical Institute of Jamaica (STATIN) for providing the shapefile. The authors would also like to thank the Ministry of Health and Wellness and the National Health Fund Jamaica, which provided funding for the Jamaica Health and Lifestyle Survey III in 2016/2017. They also would like to thank the Geoinformation Unit from both STATIN and NLA. Thanks to the JHLS III field staff, JHLS III participants and the CAIHR/ERU administrative staff and the unit driver for their support.

Contributors JAM coordinated data collection, participated in the analysis of data, wrote the first draft of the manuscript, critically reviewed the manuscript and prepared the figures and/or tables. NOY contributed to data collection, analysed the data and critically reviewed the manuscript. MKT-R contributed to the design of the study, data collection and analysis of data, and critically reviewed the manuscript. IG contributed to the design of the study, contributed to data collection and critically reviewed the manuscript. NRB, SM, DKF, KW-K, AG and TD contributed to data collection and critically reviewed the manuscript. ReW contributed to data collection, critically reviewed the manuscript and contributed to preparation of the tables. RaW contributed to the design of the study, data collection and analysis of the data, and critically reviewed the manuscript. DRW contributed to the design of the study and data collection, and critically reviewed the manuscript. TSF conceived and designed the study, oversaw the data collection, analysed the data, wrote sections of the manuscript, critically reviewed the manuscript and prepared the figures and/or tables.

Funding This research was supported by the Bernard Lown Scholars in Cardiovascular Health Program of the Department of Global Health and Population of the Harvard T H Chan School of Public Health (Grant \#: BLSCHP-1604). The JHLS III was funded by the Ministry of Health (Jamaica) and the National Health Fund, Jamaica (Award \# HPP 315).

Competing interests None declared.

Patient consent for publication Not required.

Ethics approval Ethical approval for JHLS III was granted by the University of the West Indies Ethics Committee and the Ministry of Health Ethics Committee. Additionally, ethical approval for the current project was obtained from the University of the West Indies Ethics Committee.

Provenance and peer review Not commissioned; externally peer reviewed.

Data availability statement All data relevant to the study are included in the article or uploaded as supplementary information. No additional data are available.

Supplemental material This content has been supplied by the author(s). It has not been vetted by BMJ Publishing Group Limited (BMJ) and may not have been peer-reviewed. Any opinions or recommendations discussed are solely those of the author(s) and are not endorsed by BMJ. BMJ disclaims all liability and responsibility arising from any reliance placed on the content. Where the content includes any translated material, BMJ does not warrant the accuracy and reliability of the translations (including but not limited to local regulations, clinical guidelines, terminology, drug names and drug dosages), and is not responsible for any error and/or omissions arising from translation and adaptation or otherwise.

Open access This is an open access article distributed in accordance with the Creative Commons Attribution Non Commercial (CC BY-NC 4.0) license, which permits others to distribute, remix, adapt, build upon this work non-commercially, and license their derivative works on different terms, provided the original work is properly cited, appropriate credit is given, any changes made indicated, and the use is non-commercial. See: http://creativecommons.org/licenses/by-nc/4.0/.

ORCID iD

Trevor S Ferguson http://orcid.org/0000-0002-2393-1452

\section{REFERENCES}

1 Lloyd-Jones DM, Hong Y, Labarthe D, et al. Defining and setting national goals for cardiovascular health promotion and disease reduction. Circulation 2010;121:586-613.

2 Lloyd-Jones DM, Leip EP, Larson MG, et al. Prediction of lifetime risk for cardiovascular disease by risk factor burden at 50 years of age. Circulation 2006;113:791-8.

3 Stamler J, Stamler R, Neaton JD, et al. Low risk-factor profile and long-term cardiovascular and noncardiovascular mortality and life expectancy: findings for 5 large cohorts of young adult and middleaged men and women. JAMA 1999;282:2012-8.

$4 \mathrm{Bi} \mathrm{Y}$, Jiang $\mathrm{Y}, \mathrm{He} \mathrm{J}$, et al. Status of cardiovascular health in Chinese adults. J Am Coll Cardiol 2015;65:1013-25.

5 Folsom AR, Yatsuya H, Nettleton JA, et al. Community prevalence of ideal cardiovascular health, by the American heart association definition, and relationship with cardiovascular disease incidence. $J$ Am Coll Cardiol 2011;57:1690-6.

6 Lu Y, Shen S, Qi H, et al. Prevalence of ideal cardiovascular health in Southeast Chinese adults. Int J Cardiol 2015;184:385-7.

7 Moghaddam MM, Mohebi R, Hosseini F, et al. Distribution of ideal cardiovascular health in a community-based cohort of middle East population. Ann Saudi Med 2014;34:134-42.

8 Zeng Q, Dong SY, Song ZY, et al. Ideal cardiovascular health in Chinese urban population. Int J Cardiol 2013;167:2311-7.

9 Velasquez-Melendez G, Felisbino-Mendes MS, Matozinhos FP, et al. Ideal cardiovascular health prevalence in the Brazilian population National Health Survey (2013). Rev Bras Epidemiol 2015;18 Suppl 2:97-108.

10 Wu S, Huang Z, Yang X, et al. Prevalence of ideal cardiovascular health and its relationship with the 4-year cardiovascular events in a northern Chinese industrial City. Circ Cardiovasc Qual Outcomes 2012;5:487-93.

11 de-Graft Aikins A, Kushitor M, Koram K, et al. Chronic noncommunicable diseases and the challenge of universal health coverage: insights from community-based cardiovascular disease research in urban poor communities in Accra, Ghana. BMC Public Health 2014;14 Suppl 2:S3.

12 Nayyar D, Hwang SW. Cardiovascular health issues in inner City populations. Can J Cardiol 2015;31:1130-8.

13 De Maio FG. Understanding chronic non-communicable diseases in Latin America: towards an equity-based research agenda. Global Health 2011;7:36.

14 Prabhakaran D, Jeemon P, Reddy KS. Commentary: poverty and cardiovascular disease in India: do we need more evidence for action? Int J Epidemiol 2013;42:1431-5.

15 Mberu B, Wamukoya M, Oti S, et al. Trends in causes of adult deaths among the urban poor: evidence from Nairobi urban health and demographic surveillance system, 2003-2012. J Urban Health 2015;92:422-45.

16 World Health Organization. Noncommunicable diseases fact sheet, 2015. Available: http://www.who.int/mediacentre/factsheets/fs355/ en/

17 Diez Roux AV, Mair C. Neighborhoods and health. Ann N Y Acad Sci 2010;1186:125-45

18 Connolly S, O'Reilly D, Rosato M. House value as an indicator of cumulative wealth is strongly related to morbidity and mortality risk in older people: a census-based cross-sectional and longitudinal study. Int J Epidemiol 2010;39:383-91.

19 Fone DL, Dunstan F, Christie S, et al. Council Tax valuation bands, socio-economic status and health outcome: a cross-sectional analysis from the Caerphilly health and social needs study. BMC Public Health 2006;6:115. 
20 Rehm CD, Moudon AV, Hurvitz PM, et al. Residential property values are associated with obesity among women in King County, WA, USA. Soc Sci Med 2012;75:491-5.

21 Galobardes B, Shaw M, Lawlor DA, et al. Indicators of socioeconomic position (Part 1). J Epidemiol Community Health 2006;60:7-12.

22 Lewis G, Bebbington P, Brugha T, et al. Socioeconomic status, standard of living, and neurotic disorder. The Lancet 1998;352:605-9.

23 Jackson E, Kupke V, Rossini P. The relationship between socioeconomic indicators and residential property values in Darwin: Pacific rim real estate Society 2007

24 Corvalán $\mathrm{C}$, Amigo H, Bustos $\mathrm{P}$, et al. Socioeconomic risk factors for asthma in Chilean young adults. Am J Public Health 2005;95:1375-81.

25 Ware JK. Property value as a proxy of socioeconomic status in education. Educ Urban Soc 2019;51:99-119.

26 Leonard T, Powell-Wiley TM, Ayers C, et al. Property values as a measure of neighborhoods: an application of hedonic price theory. Epidemiology 2016;27:518-24.

27 Coffee NT, Lockwood T, Hugo G, et al. Relative residential property value as a socio-economic status indicator for health research. Int $J$ Health Geogr 2013;12:22

28 Moudon AV, Cook AJ, Ulmer J, et al. A neighborhood wealth metric for use in health studies. Am J Prev Med 2011;41:88-97.

29 Henry-Lee A. The nature of poverty in the garrison constituencies in Jamaica. Environ Urban 2005:17:83-99.

30 The World Bank. The world bank in Jamaica: the world bank, 2019. Available: https://www.worldbank.org/en/country/jamaica/ overview\#1

31 Ferguson TS, Francis DK, Tulloch-Reid MK, et al. An update on the burden of cardiovascular disease risk factors in Jamaica: findings from the Jamaica health and lifestyle survey 2007-2008. West Indian Med J 2011;60:422-8

32 Ferguson TS, Younger-Coleman NOM, Tulloch-Reid MK, et al. Educational health disparities in cardiovascular disease risk factors: findings from Jamaica health and lifestyle survey 2007-2008. Front Cardiovasc Med 2017;4:28

33 Ataman SL, Cooper R, Rotimi C, et al. Standardization of blood pressure measurement in an international comparative study. J Clin Epidemiol 1996;49:869-77.

34 Ferguson TS, Tulloch Reid MK, Younger NOM, et al. Cardiovascular health in urban poor and middle income communities in Jamaica: impact of psychosocial stress, social networks, and social support. ResearchGate [Internet] 2017 https://www.researchgate.net/ publication/334281801_Cardiovascular health in urban poor and middle_income_communities_in_Jamaica_impact_of_psychosocial_ stress social networks and social support

35 Nguyen CD, Carlin JB, Lee KJ. Model checking in multiple imputation: an overview and case study. Emerg Themes Epidemiol 2017;14:8.

36 White IR, Royston P, Wood AM. Multiple imputation using chained equations: issues and guidance for practice. Stat Med 2011;30:377-99.

37 Marshall A, Altman DG, Holder RL, et al. Combining estimates of interest in prognostic modelling studies after multiple imputation: current practice and guidelines. BMC Med Res Methodol 2009;9:57.

38 StataCorp. Stata multiple imputation reference manual release 14 College Station, TX: StataCorp LLC, 2015.

39 Djoussé L, Petrone AB, Blackshear C, et al. Prevalence and changes over time of ideal cardiovascular health metrics among AfricanAmericans: the Jackson heart study. Prev Med 2015;74:111-6.

40 Harrison S, Couillard C, Robitaille J, et al. Assessment of the American Heart Association's "Life's simple 7" score in French- speaking adults from Québec. Nutr Metab Cardiovasc Dis 2019;29:684-91.

41 Janković J, Davidović M, Bjegović-Mikanović V, et al. Status of cardiovascular health in the Republic of Serbia: results from the National health survey. PLoS One 2019;14:e0214505.

$42 \mathrm{Kim}$ JI, Sillah A, Boucher JL, et al. Prevalence of the American Heart Association's "ideal cardiovascular health" metrics in a rural, crosssectional, community-based study: the Heart of New UIm Project. J Am Heart Assoc 2013;2:e000058.

43 Short VL, Gamble A, Mendy V. Racial differences in ideal cardiovascular health metrics among Mississippi adults, 2009 Mississippi behavioral risk factor surveillance system. Prev Chronic Dis 2013;10:E194.

44 Benziger CP, Zavala-Loayza JA, Bernabe-Ortiz A, et al. Low prevalence of ideal cardiovascular health in Peru. Heart 2018;104:1251-6.

45 Empana JP, Perier MC, Singh-Manoux A, et al. Cross-Sectional analysis of deprivation and ideal cardiovascular health in the Paris prospective study 3. Heart 2016;102:1890-7.

46 Gupta B, Gupta R, Sharma KK, et al. Low prevalence of AHA-Defined ideal cardiovascular health factors among urban men and women in India. Glob Heart 2015.

47 Ren J, Guo XL, Lu ZL, et al. Ideal cardiovascular health status and its association with socioeconomic factors in Chinese adults in Shandong, China. BMC Public Health 2016;16:942.

48 Seron P, Irazola V, Rubinstein A, et al. Ideal Cardiovascular Health in the southern cone of Latin America. Public Health 2018;156:132-9.

49 van Nieuwenhuizen B, Zafarmand $\mathrm{MH}$, Beune E, et al. Ideal cardiovascular health among Ghanaian populations in three European countries and rural and urban Ghana: the RODAM study. Intern Emerg Med 2018;13:845-56.

50 Younus A, Aneni EC, Spatz ES, et al. A Systematic Review of the Prevalence and Outcomes of Ideal Cardiovascular Health in US and Non-US Populations. Mayo Clin Proc 2016;91:649-70.

51 Mujahid MS, Moore LV, Petito LC, et al. Neighborhoods and racial/ ethnic differences in ideal cardiovascular health (the multi-ethnic study of atherosclerosis). Health Place 2017;444:61-9.

52 Shockey TM, Sussell AL, Odom EC. Cardiovascular Health Status by Occupational Group - 21 States, 2013. MMWR Morb Mortal Wkly Rep 2016:65:793-8.

53 Dragano N, Bobak M, Wege N, et al. Neighbourhood socioeconomic status and cardiovascular risk factors: a multilevel analysis of nine cities in the Czech Republic and Germany. BMC Public Health 2007;7:255

54 Clark AM, DesMeules M, Luo W, et al. Socioeconomic status and cardiovascular disease: risks and implications for care. Nat Rev Cardiol 2009;6:712-22.

55 Ferguson T, Younger-Coleman N, Tulloch-Reid M, et al. Educational health disparities in cardiovascular disease risk factors in Jamaica: findings from the Jamaica health and lifestyle surveys. West Indian Med J 2013;62:31.

56 Ferguson TS, Younger N, Tulloch-Reid MK, et al. Prevalence of the metabolic syndrome in Jamaican adults and its relationship to income and education levels. West Indian Med J 2010;59:265-73.

57 Ferguson TS, Younger-Coleman NOM, Tulloch-Reid MK, et al. Factors associated with elevated blood pressure or hypertension in Afro-Caribbean youth: a cross-sectional study. PeerJ 2018;6:e4385.

58 Rosengren A, Hawken S, Ounpuu S, et al. Association of psychosocial risk factors with risk of acute myocardial infarction in 11119 cases and 13648 controls from 52 countries (the INTERHEART study): case-control study. Lancet 2004;364:953-62.

59 Nguyen XT, Quaden RM, Wolfrum S, et al. Prevalence of ideal cardiovascular health metrics in the million veteran program. $A m \mathrm{~J}$ Cardiol 2018;122:347-52. 